\title{
Therapeutic Lifestyle Changes for Hypertension and Cardiovascular Risk Reduction
}

\author{
Karol Watson, MD, PhD; ${ }^{1}$ Kenneth Jamerson, MD2
}

Elevated blood pressure is the most common chronic illness in the United States, affecting more than 50 million people. Hypertension is an even greater problem in the African American community. Traditionally, management of hypertension and cardiovascular risk reduction has focused on drug therapy; however, several studies have shown the benefits of therapeutic lifestyle changes for blood pressure lowering and cardiovascular risk reduction. Therapeutic lifestyle changes to reduce blood pressure have enormous potential as a means for preventing and controlling bypertension and thereby reducing the risk of coronary heart disease. Although the reductions in blood pressure are relatively modest with these approaches, they could potentially have a beneficial impact on overall cardiovascular morbidity and mortality when applied to the whole population. Because of their high prevalence of certain cardiovascular risk factors (e.g., obesity, diabetes mellitus) and greater salt sensitivity, therapeutic lifestyle changes have particular relevance for African Americans. (J Clin Hypertens. 2003; 5(1 suppl 1):32-37) @2003 Le Jacq Communications, Inc.

$\mathrm{E}^{\mathrm{l}}$ levated blood pressure is the most common chronic illness in the United States, affecting more than 50 million people, and hypertension is an

Division of Cardiology, David Geffen School of Medicine at UCLA; Los Angeles, CA; ${ }^{1}$ Division of Hypertension, University of Michigan Medical Center, Ann Arbor, MI2

Address for correspondence:

Karol Watson, MD, PhD, UCLA School of Medicine, 10833

Le Conte Avenue, 47-123CKS, Los Angeles, CA 90095

E-mail:kwatson@mednet.ucla.edu

Manuscript received November 18, 2002;

accepted December 4, 2002 even greater health problem in the African American community. ${ }^{1}$ Approximately $33 \%$ of adult African Americans and $25 \%$ of adult white persons in the United States have hypertension.2,3 Furthermore, African Americans have higher rates of morbidity and mortality, earlier onset of hypertension, and more hypertension-related cardiovascular complications than other American ethnic groups. ${ }^{2,4}$

Traditionally, management of hypertension and cardiovascular risk reduction have focused on drug therapy. ${ }^{5}$ Although the use of antihypertensive drugs and other pharmacologic agents for cardiovascular risk reduction dominates the management of these conditions and has shown enormous benefit, several studies have also demonstrated the benefits of therapeutic lifestyle changes for blood pressure lowering and cardiovascular risk reduction. ${ }^{6-10}$

Multifaceted therapeutic lifestyle changes are an integral component in decreasing hypertension and reducing the risk for coronary heart disease (CHD).11,12 Recommendations from the Sixth Report of the Joint National Committee on Prevention, Detection, Evaluation, and Treatment of High Blood Pressure ${ }^{11}$ and more recently from the National High Blood Pressure Education Program 12 emphasize a number of therapeutic lifestyle changes for the management of hypertension. These include weight reduction for those who are overweight, moderation of alcohol intake, increased physical activity, moderation of dietary sodium, adequate intake of dietary potassium, adequate intake of dietary calcium and magnesium, cessation of smoking, and reduced intake of dietary saturated fat and cholesterol. These changes are considered essential for individuals who are more likely to develop high blood pressure, such as African Americans, the elderly, and those who 
are overweight and physically inactive or have a strong family history of hypertension.

Patients should be strongly encouraged to adopt these lifestyle modifications, particularly if they have additional risk factors for cardiovascular disease. Even when these therapeutic lifestyle changes do not reduce blood pressure to normal levels, their use can decrease the dosages of antihypertensive medications that are required. ${ }^{11}$ Because African Americans have a higher prevalence of certain cardiovascular risk factors (e.g., obesity, cigarette smoking, type 2 diabetes), they may be more responsive to lifestyle modifications than other racial groups. ${ }^{11}$ In addition, these individuals are generally more sensitive to changes in certain dietary factors (particularly sodium intake) than the general population. ${ }^{11}$

Therapeutic lifestyle changes are important for individuals with hypertension and are particularly important for those with elevated cardiovascular disease risk factors such as hyperlipidemia and diabetes. This report reviews data showing the benefit of therapeutic lifestyle changes in the management of hypertension and cardiovascular risk reduction.

\section{THERAPEUTIC LIFESTYLE CHANGES}

Because patients with hypertension are at increased risk for $\mathrm{CHD}$, therapeutic lifestyle changes that decrease cardiovascular risk are of the utmost importance. Patient education regarding therapeutic lifestyle changes to lower blood pressure, serum cholesterol levels, and the risk for $\mathrm{CHD}$ is crucial. Although many of the studies assessing the efficacy of therapeutic lifestyle changes do not specify the proportion of patients who are African American, the results are likely applicable across ethnic groups.

\section{Diet}

DASH and DASH-Sodium. Two recent trials (Dietary Approaches to Stop Hypertension [DASH] ${ }^{13}$ and DASH-Sodium ${ }^{14}$ ) have shown that dietary management can reduce blood pressure. Overall, these studies show that a diet low in saturated fat, cholesterol, and total fat that emphasizes fruits, vegetables, and low-fat dairy foods will reduce blood pressure.

The DASH trial13 studied 459 individuals with systolic blood pressure (SBP) $<160 \mathrm{~mm} \mathrm{Hg}$ and diastolic blood pressure (DBP) $80-95 \mathrm{~mm} \mathrm{Hg} ; 60 \%$ were African Americans. Subjects were randomized to one of three diets: 1) control diet; 2) a diet rich in fruits and vegetables; or 3) a combination diet rich in fruits, vegetables, and low-fat dairy products with reduced saturated and total fat (Table). ${ }^{14}$ SBP and DBP were decreased by 5.5 and $3.0 \mathrm{~mm} \mathrm{Hg}$, respectively, in those randomized to the combination diet compared to the control diet $(p<0.001)$. The effect was even greater among African Americans (6.9/3.7 $\mathrm{mm} \mathrm{Hg}$ reductions; $p<0.001$ ). Among those with hypertension at baseline, the reductions in SBP and DBP were 11.4 and $5.5 \mathrm{~mm} \mathrm{Hg}$, and these blood pressure reductions were evident within 2 weeks. Subjects randomized to the fruits-and-vegetables diet also had a decrease in blood pressure but to a lesser extent than subjects on the combination diet. The combination diet decreased SBP and DBP by 2.7/1.9 $\mathrm{mm} \mathrm{Hg}$ more than the fruits-and-vegetables diet $(p \leq 0.001)$. The benefit of the combination diet over the other diets was evident in both patients with and without hypertension.

The DASH-Sodium study ${ }^{15}$ was a randomized, multicenter trial designed to evaluate the effect of different levels of dietary sodium, in conjunction with the DASH diet, on blood pressure. This study included 412 patients (56\%-57\% African American) with an average SBP and DBP of 120-159/80-95 mm Hg. Subjects were randomized to a DASH or control diet for 1 month at each of three sodium levels $(1500,2400$, or $3300 \mathrm{mg} /$ day). The reductions in blood pressure were greatest among those on the DASH diet with the lowest sodium level, a level below that routinely recommended in national guidelines. SBP was reduced by $11.5 \mathrm{~mm} \mathrm{Hg}$ more in patients randomized to the DASH diet and a lower level of sodium than the control diet and a high level of sodium $(p<0.001)$. The effect was even greater among African American patients (difference of $12.6 \mathrm{~mm} \mathrm{Hg} ; p<0.001$ ). Restriction of dietary sodium gradually reduced blood pressure for both eating plans. The difference in SBP between the low- and high-sodium subgroups was 6.7 $\mathrm{mm} \mathrm{Hg}$ for the control diet $(p<0.001)$ and $3.0 \mathrm{~mm} \mathrm{Hg}$ for the DASH diet $(p<0.001)$. Reductions in blood pressure were seen without respect to the presence of hypertension, race, or sex. 16

Mediterranean-Type Diet and Omega-3 Fatty Acids. The Lyon Diet Heart Study ${ }^{10}$ was a prospective, randomized, secondary prevention diet modification trial designed to see if a Mediterranean diet rich in $\alpha$ linolenic acid (an omega-3 fatty acid found in large amounts in flaxseed oil) is more effective than a typical low-fat diet in preventing recurrent cardiac events among patients who had experienced a first myocardial infarction. The experimental group replaced most of their meat with chicken and replaced butter with margarine high in $\alpha$-linolenic acid. After 4 years, the experimental group had fewer cardiac events than the control group on three separate composite outcomes. This included fewer primary (cardiac death and nonfatal myocardial infarction) events (14 vs. 44 events; 


\begin{tabular}{|c|c|c|c|c|}
\hline FOOD GROUP & $\begin{array}{l}\text { DAILY } \\
\text { SERVINGS }\end{array}$ & SERVING SIZES & EXAMPLES AND NOTES & $\begin{array}{l}\text { SIGNIFICANCE OF } \\
\text { EACH FOOD GROUP }\end{array}$ \\
\hline $\begin{array}{l}\text { Grains and grain } \\
\text { products }\end{array}$ & $7-8$ & $\begin{array}{l}1 \text { slice bread, } 1 / 2 \text { cup dry } \\
\text { cereal, } 1 / 2 \text { cup cooked } \\
\text { rice, pasta, or cereal }\end{array}$ & $\begin{array}{l}\text { Whole-wheat bread, English } \\
\text { muffin, pita bread, bagel, } \\
\text { cereals, grits, oatmeal }\end{array}$ & $\begin{array}{l}\text { Major sources of } \\
\text { energy and fiber }\end{array}$ \\
\hline Vegetables & $4-5$ & $\begin{array}{l}1 \text { cup raw leafy } \\
\text { vegetable, } 1 / 2 \text { cup } \\
\text { cooked vegetable, } 6 \mathrm{oz} \\
\text { vegetable juice }\end{array}$ & $\begin{array}{l}\text { Tomatoes, potatoes, carrots, } \\
\text { peas, squash, broccoli, turnip } \\
\text { greens, collards, kale, spinach, } \\
\text { artichokes, sweet potatoes, beans }\end{array}$ & $\begin{array}{l}\text { Rich sources of } \\
\text { potassium, } \\
\text { magnesium, and fiber }\end{array}$ \\
\hline Fruits & $4-5$ & $\begin{array}{l}6 \text { oz fruit juice, } 1 \\
\text { medium fruit, } 1 / 4 \text { cup } \\
\text { dried fruit, } 1 / 2 \text { cup fresh, } \\
\text { frozen, or canned fruit }\end{array}$ & $\begin{array}{l}\text { Apricots, bananas, dates, } \\
\text { oranges, orange juice, } \\
\text { grapefruit, grapefruit juice, } \\
\text { mangoes, melons, peaches, } \\
\text { pineapples, prunes, raisins, } \\
\text { strawberries, tangerines }\end{array}$ & $\begin{array}{l}\text { Important sources of } \\
\text { potassium, } \\
\text { magnesium, and } \\
\text { fiber }\end{array}$ \\
\hline $\begin{array}{l}\text { Low-fat or } \\
\text { nonfat dairy } \\
\text { foods }\end{array}$ & $2-3$ & $\begin{array}{l}8 \text { oz milk, } 1 \text { cup yogurt, } \\
1.5 \text { oz cheese }\end{array}$ & $\begin{array}{l}\text { Skim or } 1 \% \text { milk, skim or low- } \\
\text { fat buttermilk, nonfat or low- } \\
\text { fat yogurt, part skim } \\
\text { mozzarella cheese, nonfat } \\
\text { cheese }\end{array}$ & $\begin{array}{l}\text { Major sources of } \\
\text { calcium and protein }\end{array}$ \\
\hline $\begin{array}{l}\text { Meats, poultry, } \\
\text { and fish }\end{array}$ & 2 or less & $\begin{array}{l}3 \mathrm{oz} \text { cooked meats, } \\
\text { poultry, or fish }\end{array}$ & $\begin{array}{l}\text { Select only lean; trim away } \\
\text { visible fats; broil, roast, or boil } \\
\text { instead of frying; remove skin } \\
\text { from poultry }\end{array}$ & $\begin{array}{l}\text { Rich sources of } \\
\text { protein and } \\
\text { magnesium }\end{array}$ \\
\hline $\begin{array}{l}\text { Nuts, seeds, and } \\
\text { legumes }\end{array}$ & $\begin{array}{l}\text { 4-5 per } \\
\text { week }\end{array}$ & $\begin{array}{l}1.5 \text { oz or } 1 / 3 \text { cup nuts, } \\
1 / 2 \text { oz or } 2 \text { tbsp seeds, } \\
1 / 2 \text { cup cooked legumes }\end{array}$ & $\begin{array}{l}\text { Almonds, filberts, mixed nuts, } \\
\text { peanuts, walnuts, sunflower } \\
\text { seeds, kidney beans, lentils }\end{array}$ & $\begin{array}{l}\text { Rich sources of } \\
\text { energy, magnesium, } \\
\text { potassium, protein, } \\
\text { and fiber }\end{array}$ \\
\hline *Based on 2000 & stady & 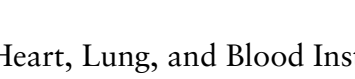 & 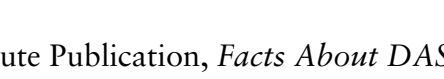 & . \\
\hline
\end{tabular}

$p=0.0001$ ); fewer primary and secondary (unstable angina, stroke, heart failure, pulmonary or peripheral embolism) events ( 27 vs. 90 events, $p=0.0001$ ); and fewer primary, secondary, and minor events requiring hospitalization (95 vs. 180 events, $p=0.0002$ ).

The largest study of omega-3 fats was the GISSI Prevenzione Trial (Gruppo Italiano per lo Studio della Sopravvivenza nell'Infarto Miocardico), ${ }^{17}$ in which more than 11,000 Italian subjects were randomized to an omega-3 fatty acid supplement (n-3 polyunsaturated fatty acid), vitamin E, or control following myocardial infarction. After 3.5 years, the omega-3 fatty acid group had a 10\% (95\% confidence interval [CI], 1-18) relative risk reduction for the composite end point (death, nonfatal myocardial infarction, and stroke). The benefit was primarily related to a decrease in the risk of death (14\% risk reduction [95\% CI, 3-24]).

The exact mechanisms of benefit of omega-3 fatty acids are not fully known but may relate to their modest blood pressure-lowering effects, their triglyceridelowering effects, or their antiplatelet effects. From epidemiologic data and clinical trial evidence, it seems that just two servings of omega- 3 fatty acid-containing fish per week are associated with a $40 \%$ decrease in CHD death. Ocean fish such as salmon, tuna, and mackerel have the highest levels of omega-3 fatty acids, although fresh water species such as lake trout and channel catfish also contain significant amounts.

Weight Reduction and Increased Physical Activity Excess body weight and a sedentary lifestyle are correlated with the development of hypertension. There has been a progressive trend toward decreased physical activity among Americans in general and African Americans in particular during the past several years, and this has contributed to the increased prevalence of obesity. For example, Kimm et al. ${ }^{18}$ recently reported that $56 \%$ of 16 - and 17-year-old African American girls participate in no leisure-time physical activity compared with $31 \%$ of white girls. In this study, a decline in physical activity was significantly associated with a higher body mass index (BMI) for both groups ( $p \leq 0.05$ for both). Excess weight (particularly abdominal obesity) and physical inactivity 
are risk factors for insulin resistance and enhance the risk for CHD.

Although therapeutic lifestyle changes such as weight loss and physical activity are frequently recommended for the treatment of hypertension in the elderly, there has been a paucity of evidence from randomized controlled trials in support of this recommendation. A 1998 trial,19,20 however, offered proof of benefit of this approach. The Trial of Nonpharmacologic Interventions in the Elderly (TONE) 19,20 was designed to determine whether weight loss or reduced sodium intake are effective in the treatment of older persons with hypertension. This was a randomized controlled trial of 875 men and women aged 60-80 years with $\mathrm{SBP}<145 \mathrm{~mm} \mathrm{Hg}$ and DBP $<85 \mathrm{~mm} \mathrm{Hg}$. All participants received treatment with a single antihypertensive medication. Of the 975 participants (proportion of African Americans not specified), 585 were obese. The 585 obese participants were randomized to reduced sodium intake, weight loss, both, or usual care, and the 390 nonobese participants were randomized to reduced sodium intake or usual care. Withdrawal of antihypertensive medication was attempted after 3 months of intervention. The main outcomes measured were high blood pressure at one or more follow-up visits, treatment with antihypertensive medication, or a cardiovascular event during follow-up (range, 15-36 months; median, 29 months).

The results of this trial showed that the combined outcome measure was less frequent among those assigned to reduced sodium intake (relative hazard ratio, $0.69 ; 95 \% \mathrm{CI}, 0.59-0.81 ; p<0.001)$ and, in obese participants, among those assigned to weight loss (relative hazard ratio, 0.70; 95\% CI, 0.57-0.87; $p<0.001)$. Relative to usual care, hazard ratios among the obese participants were $0.60(95 \% \mathrm{CI}$, $0.45-0.80 ; p<0.001)$ for reduced sodium intake alone, 0.64 (95\% CI, 0.49-0.85; $p=0.002)$ for weight loss alone, and 0.47 (95\% CI, 0.35-0.64; $p<0.001)$ for reduced sodium intake and weight loss combined. The frequency of cardiovascular events during follow-up was similar in each of the six treatment groups. Additional follow-up after the end of TONE found that the benefits of standard dietary intervention had persisted for at least 4 years. ${ }^{20}$ Forty-eight months after the end of contact with the study investigators, more patients randomized to the combined interaction group were not taking antihypertensive medication compared with the usual-care group $(23 \%$ vs. $7 \% ; p=0.012)$. It can be concluded from this study that reduced sodium intake and weight loss constitute feasible, effective, and safe therapeutic lifestyle changes for the treatment of hypertension in older persons.
Similar results were shown in the Trials of Hypertension Prevention (TOHP) phase II, ${ }^{20,21}$ which involved 2382 middle-aged men and women with high-normal blood pressure $(83-89 / \leq 140 \mathrm{~mm} \mathrm{Hg}$ ) and a BMI $110 \%-165 \%$ above normal standards. ${ }^{21,22}$ Participants were randomized to receive counseling for weight loss and/or sodium restriction (each alone and in combination) or to a control group.

Participants in the weight-reduction group achieved mean reductions in weight of 4.4, 2.0, and $0.2 \mathrm{~kg}$ at 6 , 18 , and 36 months. ${ }^{22}$ Although white participants achieved significantly greater reductions in weight than African Americans in the first 18 months of the study, the difference was not evident at 36 months. DBP and SBP decreased more in all of the active treatment groups than in the control group throughout the 36month follow-up period. Compared with the control group, blood pressure was reduced $3.7 / 2.7 \mathrm{~mm} \mathrm{Hg}$ in the weight-loss group, $2.9 / 1.6 \mathrm{~mm} \mathrm{Hg}$ in the sodiumreduction group, and 4.0/2.8 $\mathrm{mm} \mathrm{Hg}$ in the combined group ( $p<0.001$ for all groups vs. control). ${ }^{20}$ There were no racial differences in responses at all time points. There was a positive correlation between the degree of weight loss and the degree of blood pressure reduction. 22 Of note, there seemed to be a residual effect on blood pressure among those who lost weight initially but subsequently regained their lost weight, with these participants having a significantly lower relative risk $(0.68$; 95\% CI, 0.47-1.00) for hypertension compared with patients with no weight loss.

These studies show that even modest reductions in weight are associated with significant reductions in SBP and DBP. It has been estimated that each 1-kg reduction in body weight is associated with reductions in SBP and DBP, respectively, of 1.2 and $1.0 \mathrm{~mm} \mathrm{Hg} .{ }^{23}$ Such reductions in blood pressure can have a substantial clinical benefit. The recent guidelines of the National High Blood Pressure Education Program estimate that a reduction in SBP as little as $2 \mathrm{~mm} \mathrm{Hg}$ could save more than 70,000 lives in the United States each year. ${ }^{12}$

According to the American Heart Association, the goal is to achieve a BMI of $\leq 18.5 \mathrm{~kg} / \mathrm{m}^{2}$. The American Heart Association recommends that weight management be initiated when BMI is $\geq 25 \mathrm{~kg} / \mathrm{m}^{2}$ and waist circumference at the iliac crest level is $>40$ inches in men and $>35$ inches in women. ${ }^{24}$ A weight-management program should include caloric restriction and increased caloric expenditure as appropriate. Moderately-intense physical activity $(40 \%-60 \%$ of maximum oxygen consumption) can lower blood pressure. ${ }^{11}$ Increased physical activity can also reduce the risk for $\mathrm{CHD}$, improve glucose control, and improve overall well-being. ${ }^{25}$ 


\section{THERAPY FOR HYPERCHOLESTEROLEMIA}

The National Cholesterol Education Program recently revised its guidelines for the detection, evaluation, and treatment of elevated cholesterol levels (Adult Treatment Panel III [ATP III]). ${ }^{26}$ The ATP III guidelines continue to recognize low-density lipoprotein (LDL) cholesterol as the major cause of CHD. This recognition and the results of large studies showing the benefit of aggressive LDL-lowering therapy has resulted in a lowering of target LDL cholesterol levels. An LDL cholesterol level $<100 \mathrm{mg} / \mathrm{dL}$ is now classified as optimal. ${ }^{26}$ Based on an increased recognition of the importance of high-density lipoprotein (HDL) cholesterol, categoric low HDL cholesterol was increased from $<35 \mathrm{mg} / \mathrm{dL}$ to $<40 \mathrm{mg} / \mathrm{dL}$ in ATP III. The finding that elevated triglyceride levels are an independent CHD risk factor led to the lowering of triglyceride classification cutpoints to give more attention to moderate elevations. In addition, the ATP III guidelines place special emphasis on the identification of individuals with multiple metabolic risk factors (i.e., metabolic syndrome) as candidates for intensive therapeutic lifestyle changes.

Pharmacologic therapy for elevated blood cholesterol levels, primarily with statins, has been shown to decrease mortality and CHD both in the primary and secondary prevention settings (Figure). ${ }^{27}$ Diet is also an important factor for lowering serum cholesterol levels. The ATP III recommendations for the treatment of high blood cholesterol recommend a reduced intake of saturated fats $(<7 \%$ of total calories) and cholesterol $\left(<200 \mathrm{mg} /\right.$ day). ${ }^{26}$ Total fat is allowed to range from $25 \%-35 \%$ of total calories provided that saturated fats and trans-fatty acids are kept low. This is because a higher intake of unsaturated fat can help to reduce triglyceride and increase HDL cholesterol

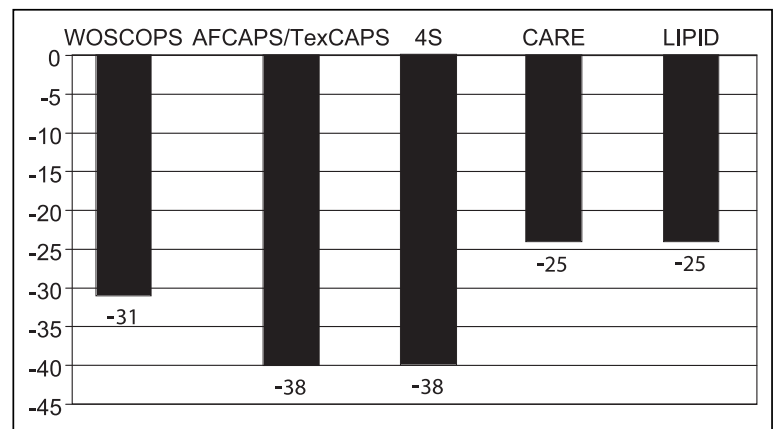

Figure. Reduction in major coronary events in primary and secondary prevention trials with medications that correct dyslipidemias, coronary heart disease death, and nonfatal myocardial infarction. ${ }^{27}$

WOSCOPS = West of Scotland Coronary Prevention Study; AFCAPS/TexCAPS=Air Force/Texas Coronary Atherosclerosis Prevention Study; $4 S=S$ candinavian Simvastatin Survival Study; CARE=Cholesterol and Recurrent Events trial; LIPID=Long-Term Intervention With Pravastatin in Ischemic Disease levels, particularly among those with the metabolic syndrome. The $\mathrm{DASH}^{28}$ diet has also been shown to produce significant reductions in total, LDL, and HDL cholesterol levels. Patients randomized to the DASH diet achieved reductions in total and LDL cholesterol levels of $13.7 \mathrm{mg} / \mathrm{dL}$ and $10.7 \mathrm{mg} / \mathrm{dL}$, respectively, more than those in the control diet group $(p<0.0001)$. The effect was similar across racial groups. Although specific studies have not been done in black subjects, the guidelines for lipid control most certainly would apply to this population.

\section{CONCLUSIONS}

Great strides have been made in reducing morbidity and mortality from heart disease in this century. However, CHD is still the single largest killer of Americans. We have seen enormous benefits with the advent of pharmacologic agents for the treatment of cardiovascular risk factors, and even greater benefits can be seen if both pharmacologic and therapeutic lifestyle measures are used in conjunction. Therapeutic lifestyle approaches to reducing blood pressure have enormous potential as a means for preventing and controlling hypertension and thereby reducing the risk of $\mathrm{CHD}$. Indeed, even if the reduction in blood pressure with therapeutic lifestyle changes is small, an enormous, beneficial impact on overall cardiovascular morbidity and mortality can be achieved when the benefits are applied to the whole US population.

\section{REFERENCES}

1 Wali RK, Weir MR. Hypertensive cardiovascular disease in African Americans. Curr Hypertens Rep. 1999;1:521-528.

2 Lackland DT, Keil JE. Epidemiology of hypertension in African Americans. Semin Nephrol. 1996;16:63-70.

3 Burt VL, Cutler JA, Higgins M, et al. Trends in the prevalence, awareness, treatment, and control of hypertension in the US population. Hypertension. 1995;26:60-69.

4 Potts JL, Thomas J. Traditional coronary risk factors in African Americans. Am J Med Sci. 1999;317:189-192.

5 Appel LJ. Nonpharmacologic therapies that reduce blood pressure: a fresh perspective. Clin Cardiol. 1999;22(7 suppl):III1-III5.

6 Elmer PJ, Grimm R Jr, Laing B, et al. Lifestyle intervention: results of the Treatment of Mild Hypertension Study (TOMHS). Prev Med. 1995;24:378-388.

7 Ornish D. Very-low fat diets. Circulation. 1999;100: 1013-1015.

8 Wilhelmsson C, Vedin JA, Elmfeldt D, et al. Smoking and myocardial infarction. Lancet. 1975;1:415-420.

9 Burr ML, Fehily AM, Gilbert JF, et al. Effects of changes in fat, fish and fibre intakes on death and myocardial reinfarction: diet and reinfarction trial. Lancet. 1989;2:757-761.

10 de Lorgeril M, Renaud S, Mamelle N, et al. Mediterranean alpha-linolenic acid-rich diet in the secondary prevention of coronary heart disease. Lancet. 1994;343:1454-1459.

11 National High Blood Pressure Education Program. The Sixth Report of the Joint National Committee on Prevention, Detection, Evaluation, and Treatment of High Blood Pressure. Bethesda, MD: National Institutes of Health; National Heart, Lung, and Blood Institute; November 1997. NIH Publication No. 98-4080. 
12 National Heart, Lung, and Blood Institute. New recommendations to prevent high blood pressure. Available at: www.nhlbi.nih.gov. Accessed October 17, 2002.

13 Appel LJ, Moore TJ, Obarzanek E, et al. A clinical trial of the effects of dietary patterns on blood pressure. DASH Collaborative Research Group. N Engl J Med. 1997;336: 1117-1124.

14 National Heart, Lung, and Blood Institute. Facts About the DASH Diet. NIH Publication No. 01-4082. Available at: http://www.nhlbi.nih.gov/health/public/heart/hbp/dash. Accessed January 7, 2008

15 Sacks FM, Svetkey LP, Vollmer WM, et al. Effects on blood pressure of reduced dietary sodium and the Dietary Approaches to Stop Hypertension (DASH) diet. DASHSodium Collaborative Research Group. $N$ Engl J Med. 2001;344:3-10.

16 Vollmer WM, Sacks FM, Ard J, et al. Effects of diet and sodium intake on blood pressure: subgroup analysis of the DASH-sodium trial. Ann Intern Med. 2001;135:1019-1028.

17 GISSI-Prevenzione Investigators. (Gruppo Italiano per lo Studio della Sopravvivenza nell'Infarto Miocardico.) Dietary supplementation with n-3 polyunsaturated fatty acids and vitamin E after myocardial infarction: results of the GISSI-Prevenzione trial. Lancet. 1999;354:447-455.

18 Kimm SY, Glynn NW, Kriska AM, et al. Decline in physical activity in black girls and white girls during adolescence. N Engl J Med. 2002;347:709-715.

19 Whelton PK, Appel LJ, Espeland MA, et al., for the TONE Collaborative Research Group. Efficacy of sodium reduction and weight loss in the treatment of hypertension in older persons: main results of the randomized, controlled Trial of Nonpharmacologic Interventions in the Elderly (TONE). JAMA. 1998;279:839-846.

20 Kostis JB, Wilson AC, Shindler DM, et al. Persistence of normotension after discontinuation of lifestyle intervention in the trial of TONE. Am J Hypertens. 2002;15:732-734.

21 Trials of Hypertension Prevention Collaborative Research Group. Effects of weight loss and sodium reduction intervention on blood pressure and hypertension incidence in overweight people with high-normal blood pressure. Arch Intern Med. 1997;157:657-667.

22 Stevens VJ, Obarzanek E, Cook NR, et al. Long-term weight loss and changes in blood pressure: results of the Trials of Hypertension Prevention, Phase II. Ann Intern Med. 2001;134:1-12.

23 Hermansen K. Diet, blood pressure and hypertension. $\mathrm{Br} J$ Nutr. 2000;83(suppl 1):S113-S119.

24 Pearson TA, Blair SN, Daniels SR, et al. AHA guidelines for primary prevention of cardiovascular disease and stroke: 2002 update. Consensus panel guide to comprehensive risk reduction for adult patients without coronary or other atherosclerotic vascular diseases. Circulation. 2002;106:388-391.

25 American Diabetes Association. Standards of medical care for patients with diabetes mellitus. Diabetes Care. 2002;25(suppl 1):S33-S89.

26 Expert Panel on Detection, Evaluation, and Treatment of High Blood Cholesterol in Adults. Executive summary of the third report of the National Cholesterol Education Program (NCEP) Expert Panel on Detection, Evaluation, and Treatment of High Blood Cholesterol in Adults (Adult Treatment Panel III). JAMA. 2001;285:2486-2497.

27 La Rosa JC, He J, Vupputuri S. Effect of statins on risk of coronary disease. A meta-analysis of randomized controlled trials. JAMA. 1999;282:2340-2346.

28 Obarzanek E, Sacks FM, Vollmer WM, et al. Effects on blood lipids of a blood pressure-lowering diet: the Dietary Approaches to Stop Hypertension (DASH) trial. Am J Clin Nutr. 2001;74:80-89. 